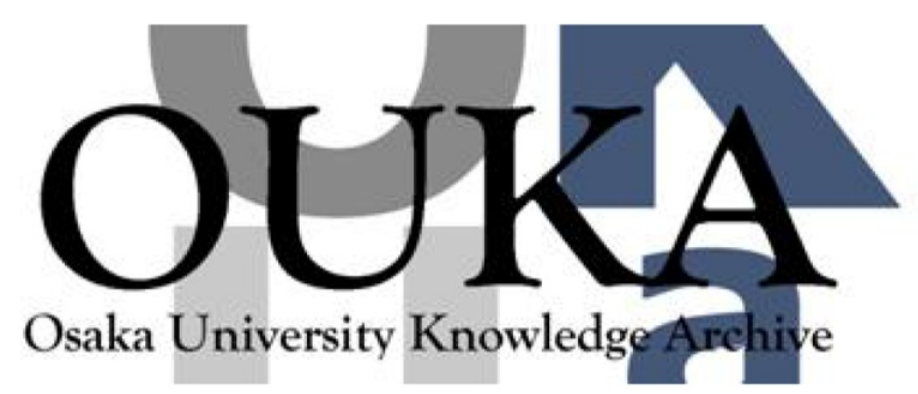

\begin{tabular}{|c|c|}
\hline Title & $\begin{array}{l}\text { Large-scale SPH simulations of droplet impact } \\
\text { onto a liquid surface up to the consequent } \\
\text { formation of Worthington jet }\end{array}$ \\
\hline Author (s) & $\begin{array}{l}\text { Nishio, Naoto; Yamana, Kentaro; Yamaguchi, } \\
\text { Yasutaka et al. }\end{array}$ \\
\hline Citation & $\begin{array}{l}\text { International Journal for Numerical Methods in } \\
\text { Fluids. } 63(12) \text { p. } 1435-p .1447\end{array}$ \\
\hline Issue Date & $2010-08-30$ \\
\hline oaire:version & AM \\
\hline URL & https://hdl. handle. net/11094/82379 \\
\hline rights & $\begin{array}{l}\text { This is the peer reviewed version of the } \\
\text { following article: Nishio, N., Yamana, K., } \\
\text { Yamaguchi, Y., Inaba, T., Kuroda, K., Nakajima, } \\
\text { T., Ohno, K. and Fujimura, H. (2010), Large- } \\
\text { scale SPH simulations of droplet impact onto a } \\
\text { liquid surface up to the consequent formation } \\
\text { of Worthington jet. Int. J. Numer. Meth. } \\
\text { Fluids, } 63 \text { : } 1435-1447 \text {, which has been published } \\
\text { in final form at } \\
\text { https://doi. org/10.1002/fld. } 2141 \text {. This article } \\
\text { may be used for non-commercial purposes in } \\
\text { accordance with Wiley Terms and Conditions for } \\
\text { Self-Archiving. }\end{array}$ \\
\hline Note & \\
\hline
\end{tabular}

Osaka University Knowledge Archive : OUKA

https://ir. Library. osaka-u. ac. jp/ 


\section{Large-Scale SPH Simulations of Droplet Impact onto a Liquid Surface up to the Consequent Formation of Worthington Jet}

\begin{tabular}{|c|c|}
\hline Journal: & International Journal for Numerical Methods in Fluids \\
\hline Manuscript ID: & FLD-08-0437.R1 \\
\hline Wiley - Manuscript type: & Research Article \\
\hline \multicolumn{2}{|l|}{$\begin{array}{r}\text { Date Submitted by the } \\
\text { Author: }\end{array}$} \\
\hline Complete List of Authors: & $\begin{array}{l}\text { Nishio, Naoto; Osaka University, Department of Mechanical } \\
\text { Engineering } \\
\text { Yamana, Kentaro; Osaka University, Department of Mechanical } \\
\text { Engineering } \\
\text { Yamaguchi, Yasutaka; Osaka University, Department of Mechanical } \\
\text { Engineering } \\
\text { Inaba, Takehiko; Osaka University, Department of Mechanical } \\
\text { Engineering } \\
\text { Kuroda, Koji; Dai Nippon Printing Co., Ltd., Nano Science Research } \\
\text { Center } \\
\text { Nakajima, Tadashi; Dai Nippon Printing Co., Ltd., Nano Science } \\
\text { Research Center } \\
\text { Ohno, Kouhei; Dai Nippon Printing Co., Ltd., Nano Science Research } \\
\text { Center } \\
\text { Fujimura, Hideo; Dai Nippon Printing Co., Ltd., Nano Science } \\
\text { Research Center }\end{array}$ \\
\hline Keywords: & $\begin{array}{l}\text { Free surface, Particle methods, Meshfree methods, Two phase } \\
\text { flows, Explicit, Dynamical systems }\end{array}$ \\
\hline
\end{tabular}

\section{(s) ScholarONE" \\ Manuscript Central}




\title{
Large-Scale SPH Simulations of Droplet Impact onto a Liquid Surface up to the Consequent Formation of Worthington Jet
}

\author{
Naoto Nishio ${ }^{1}$, Kentaro Yamana ${ }^{1}$, Yasutaka Yamaguchi ${ }^{1, *, \dagger}$, Takehiko Inaba ${ }^{1}$, \\ Koji Kuroda $^{2}$, Tadashi Nakajima ${ }^{2}$, Kouhei Ohno ${ }^{2}$ \& Hideo Fujimura ${ }^{2}$ \\ ${ }^{1}$ Department of Mechanical Engineering, Osaka University, Japan \\ ${ }^{2}$ Nano Science Research Center, Dai Nippon Printing Co., Ltd., Japan \\ ${ }^{*}$ Correspondence to: Yasutaka Yamaguchi, Department of Mechanical Engineering, Osaka \\ University, 2-1 Yamadaoka, Suita, Osaka 565-0871, Japan. \\ †E-mail: yamaguchi@mech.eng.osaka-u.ac.jp
}

\section{SUMMARY}

In this study, the whole process of liquid droplet impact onto a liquid surface up to the consequent formation of the central column was simulated using the SPH (Smoothed Particle Hydrodynamics) method, and compared with an experiment using a high-speed video camera. The surface tension tensor for the particle-based expression was adequately included as the gradient of the surface tension and that enabled the simulation leading to the formations of crater and crown as well as the consequent central column. The simulated time series of the crater depth and diameter and crown height corresponded quantitatively well with the experimental result up to the rebound motion while discrepancies remained as a lower central column height in the simulation, and this seemed to be ascribed to the difficulty in realizing the complex surface structure which inevitably appeared in the fast rebound motion.

KEY WORDS: Smoothed particle hydrodynamics; Droplet impact; Splash; Surface tension

\section{INTRODUCTION}

Since the pioneering work of Worthington [1], studies on the single liquid droplet impact onto a liquid surface has long been a topic of interest not only because the structure itself known as a 'milk crown' is purely fascinating but also because the liquid contact and consequent mist and droplet generations are commonly seen in the field of engineering, e.g., fuel injection, ink-jet printing, or 
spray coating. The control or suppression of such mist generation is essential especially for the recent high-speed and precise processes in the relief or gravure printing because a single tiny mist induces severe print defects.

The post-impact droplet motion at a low impact velocity is classified into floating, bouncing and coalescence [2]. At a higher impact velocity, a cylindrical or crown-like structure is formed on the interface and secondary droplets are then ejected from the crown as a splash. Consequently, a liquid column rises up in the center of the impact crater called 'Worthington jet' named after the pioneer.

Numbers of further experimental studies have been carried out focusing on the effects of the surface tension [3], fluid properties and liquid thickness [4] on the impact process. On the other hand, numerical simulations are performed as well primarily to realize the crown and splash formations using VOF [5] and MPS [6] methods, however, quite a few studies were capable of simulating the consequent formation of the Worthington jet. This is basically due to the difficulties in catching the fast-moving interface with a large curvature in mesh-based methods, or in the proper representation of the surface tension in particle based methods besides the system size requirement.

In this study, the whole process of liquid droplet impact onto a liquid surface up to the formation of the Worthington jet is simulated using the SPH (Smoothed Particle Hydrodynamics) method with an appropriate expression of the surface tension, and qualitative and quantitative comparisons with an experiment using a high-speed video camera are provided.

\section{METHOD}

\subsection{SPH method}

In the SPH method, a fluid is represented by a group of particles that carry the physical information of the flow field with a spatial distribution expressed by a smoothing kernel. An arbitrary quantity $A$ of a particle at position $\boldsymbol{r}_{a}$ and its gradient is described using the smoothing kernel $W$ as:

$$
\begin{aligned}
& A\left(\boldsymbol{r}_{a}\right)=\sum_{b} m_{b} \frac{A_{b}}{\rho_{b}} W\left(\boldsymbol{r}_{a}-\boldsymbol{r}_{b}, h\right) \\
& \nabla A\left(\boldsymbol{r}_{a}\right)=\sum_{b} m_{b} \frac{A_{b}}{\rho_{b}} \nabla W\left(\boldsymbol{r}_{a}-\boldsymbol{r}_{b}, h\right)
\end{aligned}
$$

where $m_{b}, \rho_{b}$ and $A_{b}$ denote the mass, density and quantity $A$ of the nearby particle $b$, respectively while $h$ is the smoothing length of the kernel. Note that the summation includes the particle $a$ itself as well.

For the kernel distribution function, we use a cubic spline form normalized for three dimensions as follows: 
where $r$ denotes the distance between two particles. The smoothing length $h$ here is given by $h=$ $1.3 s_{0}$ with $s_{0}$ as the initial distance between neighboring particles. This roughly mimics a Gaussian distribution function with a cut-off length of $2 h$. For simplification, we abbreviate the relative vector $\boldsymbol{r}_{a}-\boldsymbol{r}_{b}$ and kernel $W\left(\left|\boldsymbol{r}_{a}-\boldsymbol{r}_{b}\right|, h\right)$ as $\boldsymbol{r}_{a b}$ and $W_{a b}^{h}$, respectively in the following formula.

The density in the bulk is evaluated by:

$$
\rho_{a}^{h}=\sum_{b} m_{b} W_{a b}^{h}
$$

The total mass conservation is automatically satisfied as long as the number of particles is unchanged. An alternative density expression with a long smoothing length $H=1.5 h$ is used as well simply for the stable evaluation of the surface tension described later.

In the SPH method, a flow governed by the Navier- Stokes $(\mathrm{N}-\mathrm{S})$ equations as a continuum is approximated as the group motion of particles. The SPH momentum equation of a particle $a$ including the surface tension term $\boldsymbol{a}_{s}$ in this study is given as follows:

$$
\frac{d \boldsymbol{v}_{a}}{d t}=-\sum_{b} m_{b}\left\{\left(\frac{P_{a}}{\left(\rho_{a}^{h}\right)^{2}}+\frac{P_{b}}{\left(\rho_{b}^{h}\right)^{2}}\right) \nabla_{a} W_{a b}^{h}-\prod_{a b}\right\}+\left(\boldsymbol{a}_{s}\right)_{a}
$$

where $\boldsymbol{v}$ and $P$ are the velocity and pressure, respectively. The first two terms in the summation of the right-hand side are equivalent to the pressure gradient in the N-S equations while $\Pi$ is the Newtonian viscous stress.

The viscous force $\Pi$ in Eq. 5 is expressed as in Eq. 6 using the viscosity $\mu$ and relative velocity $\boldsymbol{v}_{a b}$ with $\eta^{2}=0.01 h^{2}$ appended to avoid the singularity at $\left|\boldsymbol{r}_{a b}\right|=0$.

$$
\prod_{a b}=\left(\frac{\mu_{a}}{\left(\rho_{a}^{h}\right)^{2}}+\frac{\mu_{b}}{\left(\rho_{b}^{h}\right)^{2}}\right) \frac{\boldsymbol{r}_{a b}\left(\boldsymbol{v}_{a b} \cdot \nabla_{a} W_{a b}^{h}\right)+\boldsymbol{v}_{a b}\left(\boldsymbol{r}_{a b} \cdot \nabla_{a} W_{a b}^{h}\right)}{\left|\boldsymbol{r}_{a b}\right|^{2}+\eta^{2}}
$$

The pressure used in Eq. 5 is given by the following equation of state [7]:

$$
P=P_{0}\left\{\left(\frac{\rho^{h}}{\rho_{0}}\right)^{\chi}-1\right\}
$$

where $P_{0}$ and $\rho_{0}$ denote the reference pressure scale and density, respectively with a characteristic exponent $\chi=7$. As it is well established that SPH is unstable when attractive forces act between particles [8-10], the pressure of a particle with a density $\rho^{h}$ smaller than $\rho_{0}$, which appears at a free surface, is set to zero in this study to avoid attractive force leading to the instability in the calculation. The pressure scale factor $P_{0}$ in Eq. 7 is given by: 


$$
P_{0}=\frac{c_{s}^{2} \rho_{0}}{\chi}=\frac{100 V^{2} \rho_{0}}{\chi}
$$

where $c_{s}$ and $V$ are the sound speed and characteristic fluid velocity, respectively. The Mach number is equal to 0.1 here.

The surface tension term $\boldsymbol{a}_{s}$ in Eq. 5 is formulated as the interaction between particles referring [11] in a way that the total momentum is conserved. Different from ordinary expression evaluating the curvature at the surface, the surface tension here is expressed as the gradient of the surface tension tensor $T_{i j}$ as:

$$
\left(\boldsymbol{a}_{s}\right)_{a}=\left(\frac{1}{\rho} \frac{\partial T_{i j}}{\partial x_{j}}\right)_{a}=\sum_{b} m_{b}\left\{\frac{\left(T_{i j}\right)_{a}}{\left(\rho_{a}^{H}\right)^{2}}+\frac{\left(T_{i j}\right)_{b}}{\left(\rho_{b}^{H}\right)^{2}}\right\} \nabla_{a, j} W_{a b}^{H}
$$

where $\nabla_{a, j} W_{a b}$ is the $j$-th direction component of the kernel gradient $W_{a b}$ with respect to particle $a$ using a long smoothing distance $H$. The dummy index $j$ indicates the summation. The surface tension tensor $T_{i j}$ is written as:

$$
T_{i j}=\alpha \sigma|\boldsymbol{n}|\left(\delta_{i j}-\hat{\boldsymbol{n}}_{i} \hat{\boldsymbol{n}}_{j}\right)
$$

where $\sigma$ and $\delta_{i j}$ denote the surface tension coefficient and Kronecker's delta, respectively while $\boldsymbol{n}$ and $\hat{\boldsymbol{n}}$ are the surface normal and its unit normal explained below. An intensity parameter $\alpha=4.5$ is multiplied to Eq. 10 so that the strength of the surface tension in the SPH expression here corresponds to the actual value. This was preliminary determined through the oscillation frequency of a droplet formed using the SPH simulation [12].

For tracking the interface, we use the color function $c$ of the particles given by:

$$
c_{a}=\sum_{b} \frac{m_{b}}{\rho_{b}^{H}} W_{a b}^{H}
$$

A long smoothing length $H$ is adopted here as well. The surface normal $\boldsymbol{n}$ in Eq. 10 is calculated as the gradient of this color function as:

$$
\boldsymbol{n}_{a}=\sum_{b} \frac{m_{b}}{\rho_{b}^{h}}\left(c_{b}-c_{a}\right) \nabla_{a} W_{a b}^{h}
$$

To avoid the singularity, the unit normal $\hat{\boldsymbol{n}}$ is redefined as in Eq. 13 with $\varepsilon=0.01 / H$.

$$
\hat{\boldsymbol{n}}=\left\{\begin{array}{cc}
\boldsymbol{n} /|\boldsymbol{n}|, & |\boldsymbol{n}|>\varepsilon \\
0, & |\boldsymbol{n}| \leq \varepsilon
\end{array}\right.
$$

As well as the axi-symmetric oscillation of a single droplet, the binary droplet collision processes and the ensuing migration or detachment depending on the offset were successfully simulated using this expression [12].

2.2. Simulation system 


\subsection{Impact process}

Figure 1 shows the simulation snapshots of the droplet impact onto a liquid surface at a velocity $U_{0}$ of $3.13 \mathrm{~m} / \mathrm{s}$, where a cross section with a thickness of $1 \mathrm{~mm}$ including the impinging axis is depicted for the three-dimensional simulation with the elapsed time $t$ after the impact. Small splashing mists are ejected just after the impact [Figure 1(c)] and a hemispherical crater grows with a crown-like rim. The crater depth and crown height reach the maximum at about $20 \mathrm{~ms}$ [Figure 1(e)] while the crater further extends to the lateral direction. Due to the rebound motion concentrated toward the crater center, a prominent peak structure appears at $t=60 \mathrm{~ms}$ [Figure. 1(h)] and continues to rise up to form a central column called 'Worthington jet.'

Figure 2 shows the snapshots of the corresponding experiment using a high-speed video camera with the same conditions. Formations of the crater, crown-like rim as well as the Worthington jet agree well with the simulation result. However, the central column appears later and its final height is apparently lower in the simulation, and the rebounding crater is rather skewed from a hemispherical shape in the experiment as shown in Figure 2 (e).

Figures 3 and 4 display the comparison between simulation and experiment for a slower impact velocity $U_{0}$ of $2.42 \mathrm{~m} / \mathrm{s}$. Similar to the case for $U_{0}=3.13 \mathrm{~m} / \mathrm{s}$, the crater and crown formations can be seen both for simulation and experiment while both are smaller, and the consequent crater 
rebound takes place earlier than in Figures 1 and 2. The central column appears earlier with a sharp peak structure and it erects up higher in the experiment, which results in the droplet detachment above the Worthington jet. Except for this difference, however, the structural feature and the time scale are well reproduced in the simulation.

\subsection{Quantitative comparison between simulation and experiment}

In order to further compare the simulations with experiments, the time series of the size information of the crater and crown in the experiment are extracted from the high-speed movie using an image processing software developed in our group. Figure 5 depicts the comparison between simulation and experiment regarding the time series of the crater depth for two impact velocities $U_{0}$, where the height from the initial surface level to the deepest point of the crater is defined as the depth $D$, i.e., the depth takes a negative value during the crater formation. Both for $U_{0}=3.13$ and $2.42 \mathrm{~m} / \mathrm{s}$, the simulated initial profiles toward the maximum depth up to $15 \mathrm{~ms}$ agree very well with the experiment. The rebound velocity, which appears as the gradient after $30 \mathrm{ms,}$, is faster in the experiment for both impact velocities, and this indicated that the rebound force is underestimated in the simulation consequently resulting in a lower column height.

Figure 6 shows the time series of the crater diameter, where the crater diameter $\phi$ is determined at the initial surface level. As seen in the snapshots in Figures 1-4, the apparent crater diameter continues to increase even in the rebound process. Similar to the crater depth in Figure 5, the initial simulated profiles until $10 \mathrm{~ms}$ correspond well with the experiment for both impact velocities, and the apparent difference is observed in the post-growth rebound motion.

Figure 7 displays the comparison regarding the crown height $H$, which is evaluated as the height defined from the initial surface level. Although the exact trace including mist detachments is rather difficult, the initial and decay profiles in the simulation agree well with the experiment for both impact velocities.

\subsection{Pressure and velocity distributions}

Figures 8 and 9 shows the pressure and velocity fields upon the droplet impact onto a liquid surface for both impact velocities $U_{0}=3.13$ and $2.42 \mathrm{~m} / \mathrm{s}$, corresponding to the simulation in Figures 1 and 3. Different from the cross sectional view in Figures 1 and 3, axi-symmetric average is displayed here. In both cases, the pressure just below the impinging point rises up above at $5 \mathrm{~ms}$ after the impact, and this induces outward upflow around the crater up to $20 \mathrm{~ms}$ in the liquid film. Upon the recovery process after $30 \mathrm{~ms}$, inflow concentrating toward the center leads to the pressure rise beneath the crater, and the concentrated flow is released as the upward jet.

\subsection{Discussions}




\section{REFERENCES}

1. Worthington, A.M. A Study of Splashes 1908. Longman and Green, London.

2. Rein, M. Phenomena of liquid drop impact on solid and liquid surface. Fluid Dynamics Research 1993; 12: 61-93.

3. Manzello S.L., Yang, J.C. An experimental study of a water droplet impinging on a liquid surface. Experiments in Fluids 2002; 32: 580-589.

4. Vander Wal, R.L., Berger, G.M., Mozes, S.D. Droplets splashing upon films of the same fluid of various depths. Experiments in Fluids 2006;40: 33-52.

5. Nikolopoulos, N., Theodorakakos, A., Bergeles, G. Normal impingement of a droplet onto a wall film: a numerical investigation. International Journal of Heat and Fluid Flow 2005; 26: 119-132.

6. Xie, H., Koshizuka, S., Oka, Y. Numerical simulation of liquid drop deposition in annular-mist flow regime of boiling water reactor. Journal of Nuclear Science and Technology 2004; 41: No. $5,569-578$. 
7. Monaghan, J.J. Simulating free surface flows with SPH. Journal of Computational Physics 1994; 110: 399-406.8. Morris, J.P., Fox, P.J., Zhu, Y. Modeling low Reynolds number incompressible flows using SPH. Journal of Computational Physics 1997; 136: 214-226.

9. Balsara, D.S. Von-Neumann stability analysis of Smoothed Particle Hydrodynamics: Suggestion for optimal algorithms. Journal of Computational Physics 1995; 121: 357-372.

10. Swegle, J.W., Hicks, D.L., Attaway, S.W. Smoothed Particle Hydrodynamics stability analysis. Journal of Computational Physics 1995; 116: 123-134.

11. Morris, J.P. Simulating surface tension with smoothed particle hydrodynamics. International Journal for Numerical Methods in Fluids 2000; 33: 333-353.

12. Yamana, K., Inaba, T., Yamaguchi, Y. SPH simulations on the droplet motion. Proceedings of the JSME 19th Computational Mechanics Conference 2006; 345-346 (in Japanese). Movies for binary droplet collision are available at: http://www-gcom.mech.eng.osaka-u.ac.jp/gallery/droplet/droplet.html.

13. Colagrossi, A., Landrini, M. Numerical simulation of interfacial flows by smoothed particle hydrodynamics. Journal of Computational Physics 2003; 191: 448-475. 
Table 1 Calculation parameters.

\begin{tabular}{|c|c|c|}
\hline density, $\rho\left(\mathrm{kg} / \mathrm{m}^{3}\right)$ & \multicolumn{2}{|c|}{$1.10 \times 10^{3}$} \\
\hline viscosity, $\mu(\mathrm{Pa} \cdot \mathrm{s})$ & \multicolumn{2}{|c|}{$3.50 \times 10^{-3}$} \\
\hline surface tension coefficient, $\sigma(\mathrm{N} / \mathrm{m})$ & \multicolumn{2}{|c|}{$6.70 \times 10^{-2}$} \\
\hline initial spacing between particles, $s_{0}(\mathrm{~mm})$ & \multicolumn{2}{|c|}{0.25} \\
\hline lateral calculation region, $X \times Y\left(\mathrm{~mm}^{2}\right)$ & \multicolumn{2}{|c|}{$40 \times 40$} \\
\hline liquid film thickness, $T(\mathrm{~mm})$ & \multicolumn{2}{|c|}{10} \\
\hline number of particles for liquid film & \multicolumn{2}{|c|}{$1,024,000(160 \times 160 \times 40)$} \\
\hline droplet diameter, $d(\mathrm{~mm})$ & \multicolumn{2}{|c|}{4} \\
\hline number of particles for impinging droplet & \multicolumn{2}{|c|}{1791} \\
\hline initial distance between droplet and film surface & \multicolumn{2}{|c|}{$2 s_{0}$} \\
\hline impact velocity, $U_{0}(\mathrm{~m} / \mathrm{s})$ & 2.42 & 3.13 \\
\hline corresponding free falling height (mm) & 300 & 500 \\
\hline Weber number, $W e$ & 385 & 643 \\
\hline Reynolds number, $R e$ & 3042 & 3935 \\
\hline Ohnesorge number, $\mathrm{Oh}$ & \multicolumn{2}{|c|}{$6.45 \times 10^{-3}$} \\
\hline
\end{tabular}




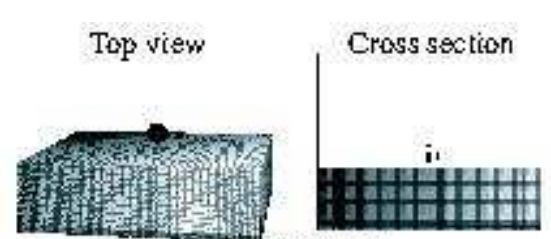

(a) $0 \mathrm{~ms}$

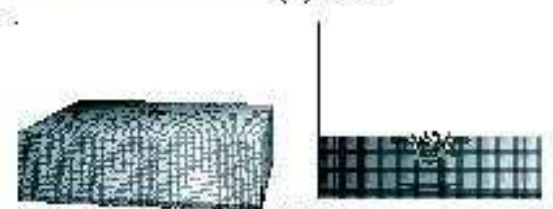

(b) $2 \mathrm{~ms}$

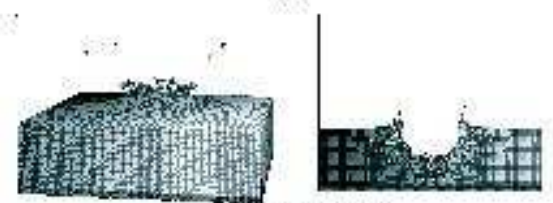

(c) $5 \mathrm{~ms}$

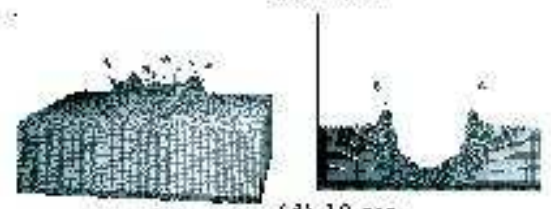

(d) $10 \mathrm{~ms}$

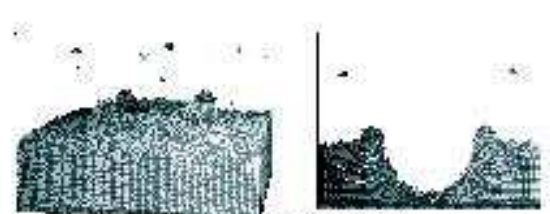

(e) $20 \mathrm{~ms}$

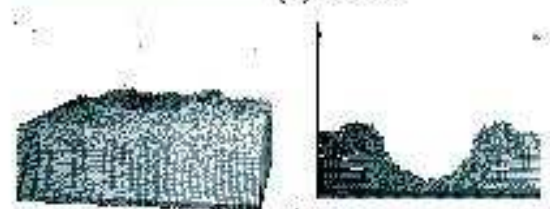

(f) $30 \mathrm{~ms}$

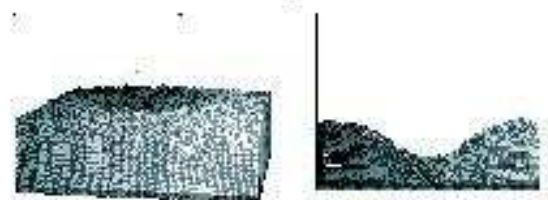

(g) $40 \mathrm{~ms}$
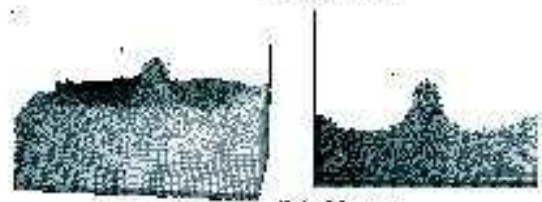

(h) $60 \mathrm{~ms}$

Simulation snapshots of the droplet impact onto a liquid surface $\left(U_{0}=3.13 \mathrm{~m} / \mathrm{s}\right)$. $161 \times 129 \mathrm{~mm}(72 \times 72 \mathrm{DPI})$ 


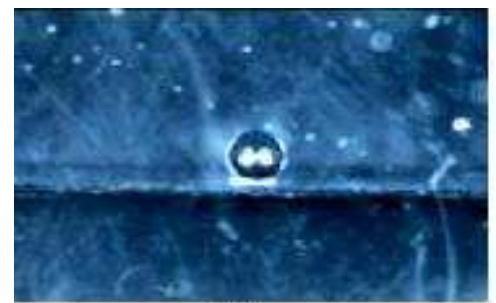

(a) $0 \mathrm{~ms}$

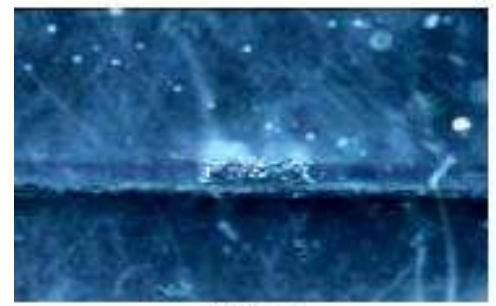

(b) $2 \mathrm{~ms}$

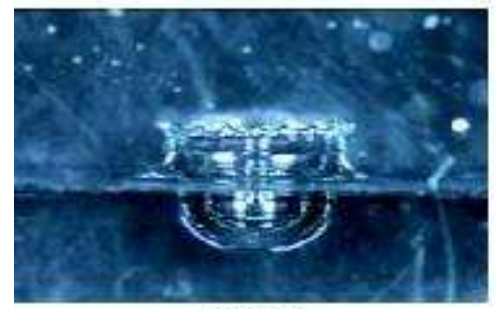

(c) $5 \mathrm{~ms}$

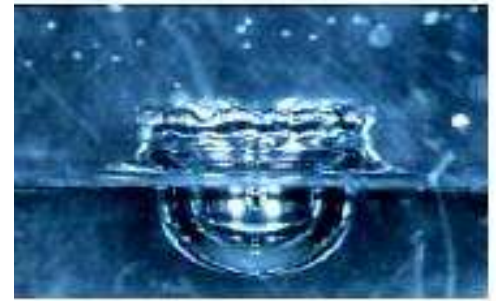

(d) $10 \mathrm{~ms}$

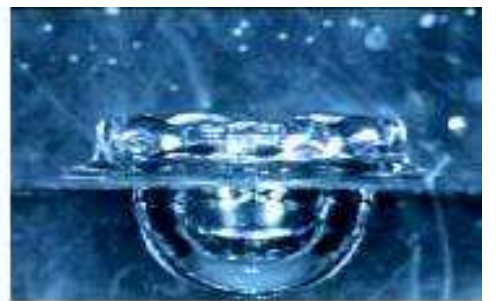

(e) $20 \mathrm{~ms}$

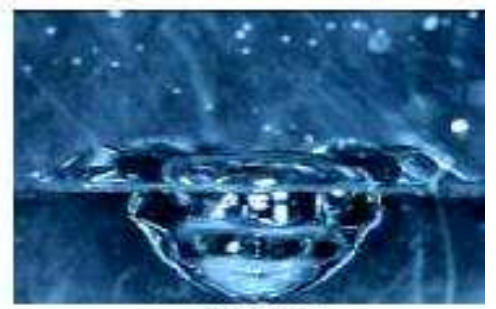

(t) $30 \mathrm{~ms}$

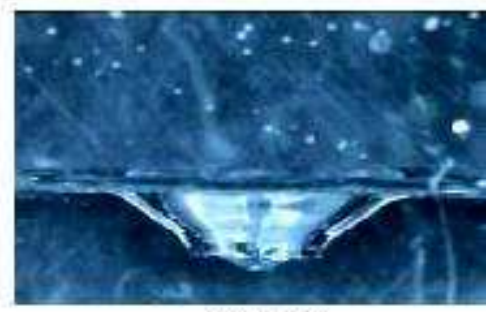

(g) $40 \mathrm{~ms}$

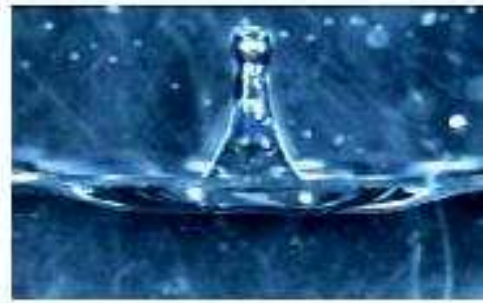

(h) $60 \mathrm{rms}$

Experimental snapshots of the droplet impact onto a liquid surface $\left(U_{0}=3.13 \mathrm{~m} / \mathrm{s}\right)$. $136 \times 188 \mathrm{~mm}(72 \times 72 \mathrm{DPI})$ 


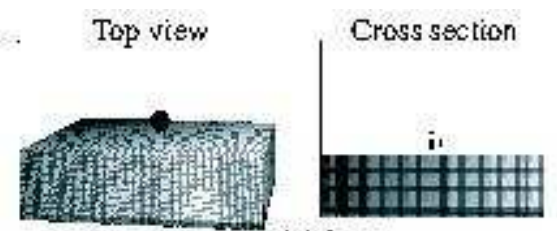

(a) $0 \mathrm{~ms}$

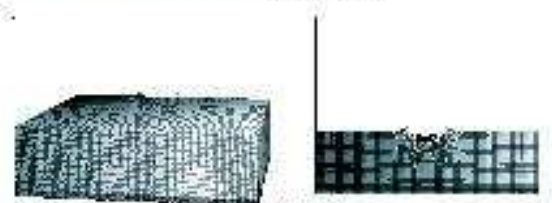

(b) $2 \mathrm{~ms}$

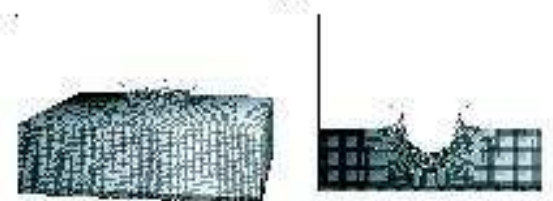

(c) $5 \mathrm{~ms}$

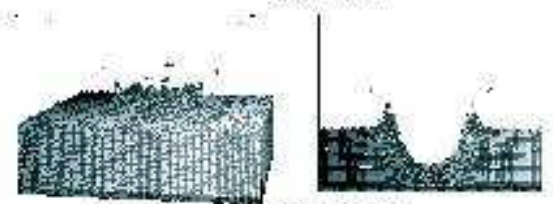

(d) $10 \mathrm{~ms}$

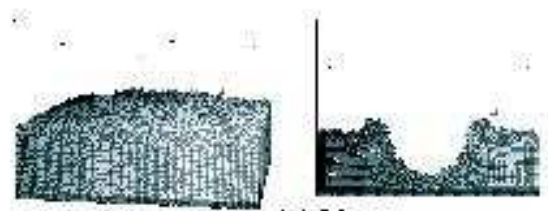

(e) $20 \mathrm{~ms}$

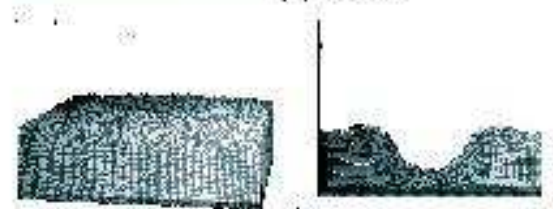

(f) $30 \mathrm{~ms}$

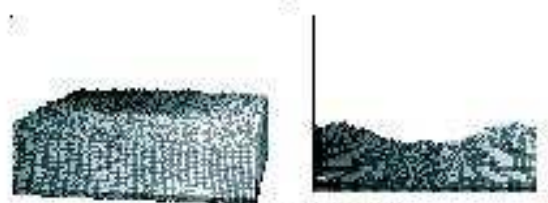

(B) $40 \mathrm{~ms}$

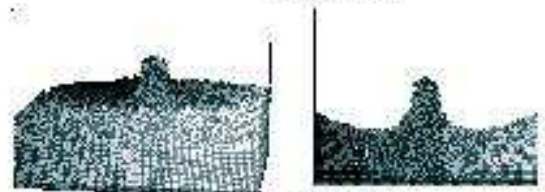

(h) $60 \mathrm{~ms}$

Simulation snapshots of the droplet impact onto a liquid surface $\left(U_{0}=2.42 \mathrm{~m} / \mathrm{s}\right)$. $161 \times 129 \mathrm{~mm}(72 \times 72 \mathrm{DPI})$ 


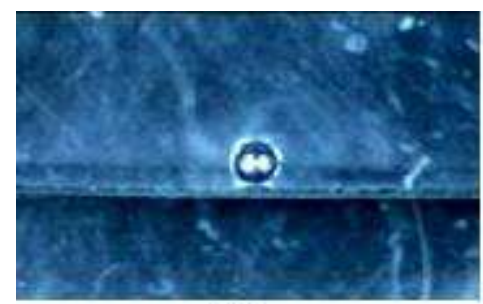

(a) $0 \mathrm{~ms}$

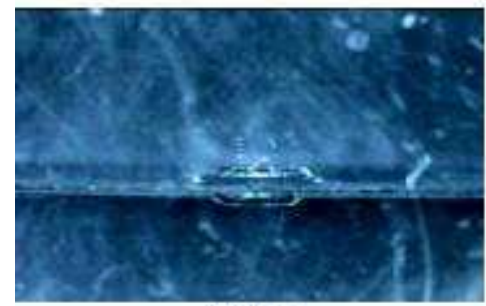

(b) $2 \mathrm{~ms}$

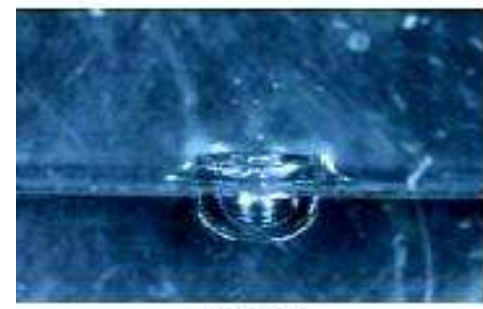

(c) $5 \mathrm{~ms}$

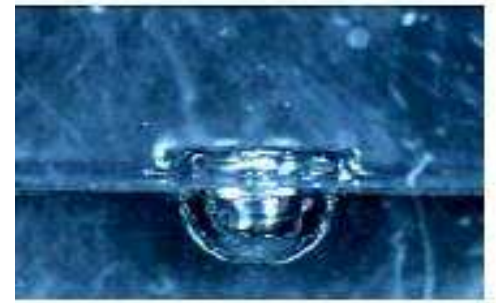

(d) $10 \mathrm{~ms}$

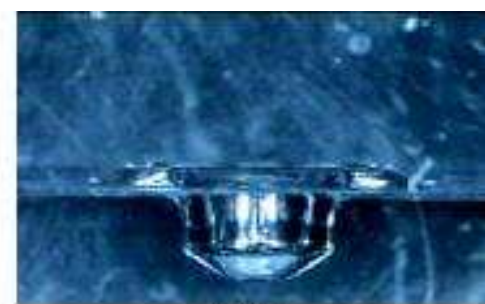

(e) $20 \mathrm{~ms}$

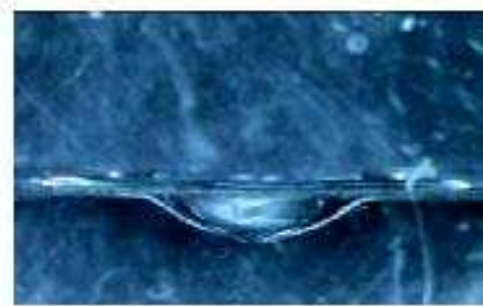

(t) $30 \mathrm{~ms}$

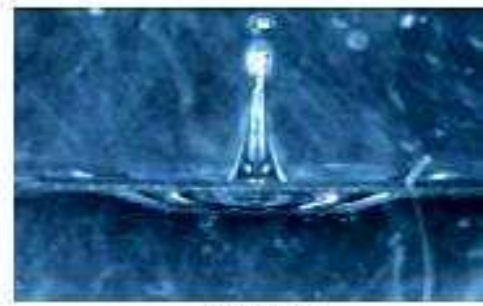

(B) $40 \mathrm{~ms}$

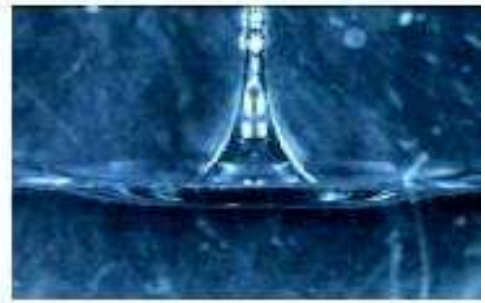

(h) $60 \mathrm{~ms}$

Experimental snapshots of the droplet impact onto a liquid surface $\left(U_{0}=2.42 \mathrm{~m} / \mathrm{s}\right)$. $136 \times 188 \mathrm{~mm}(72 \times 72 \mathrm{DPI})$ 


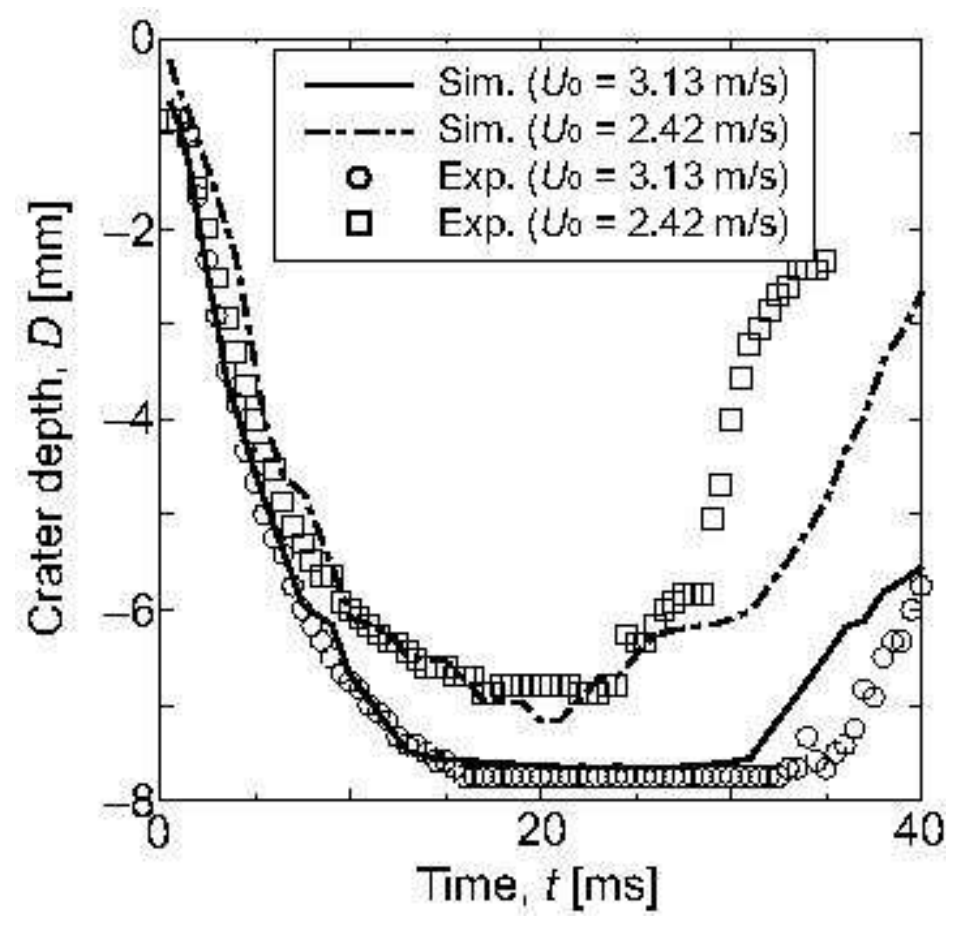

Comparison of crater depth between simulation and experiment. $125 \times 123 \mathrm{~mm}(72 \times 72 \mathrm{DPI})$ 


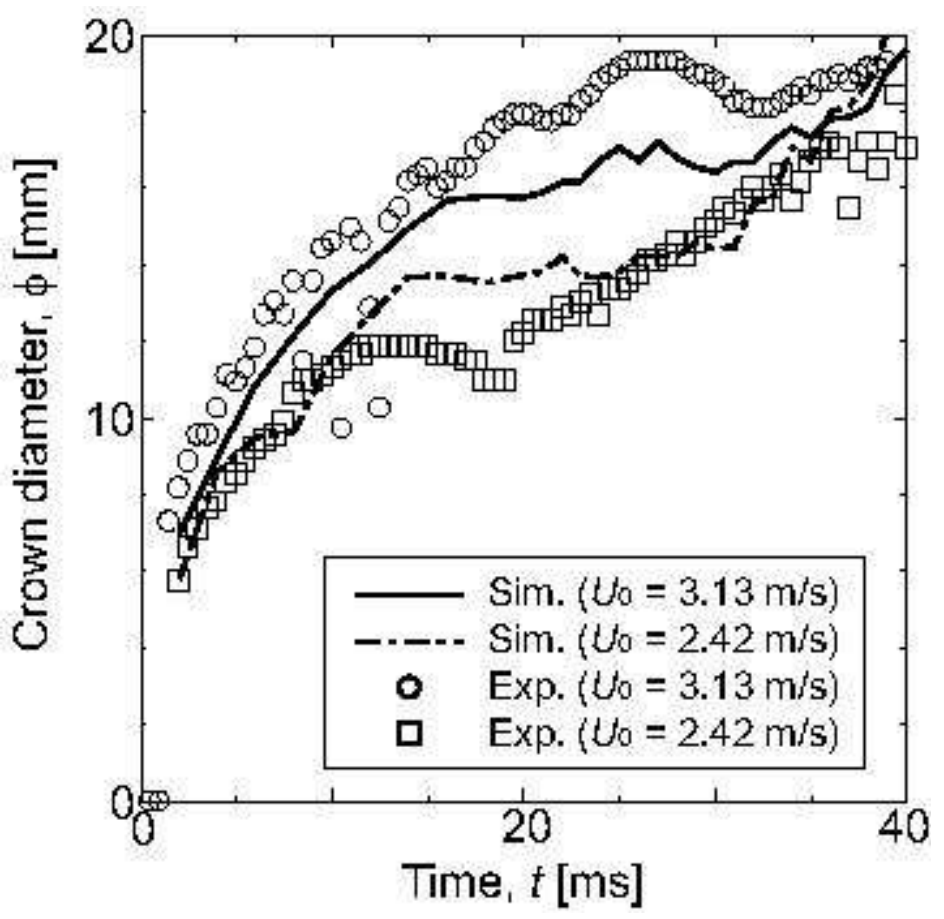

Comparison of crater diameter between simulation and experiment. $125 \times 122 \mathrm{~mm}(72 \times 72 \mathrm{DPI})$ 


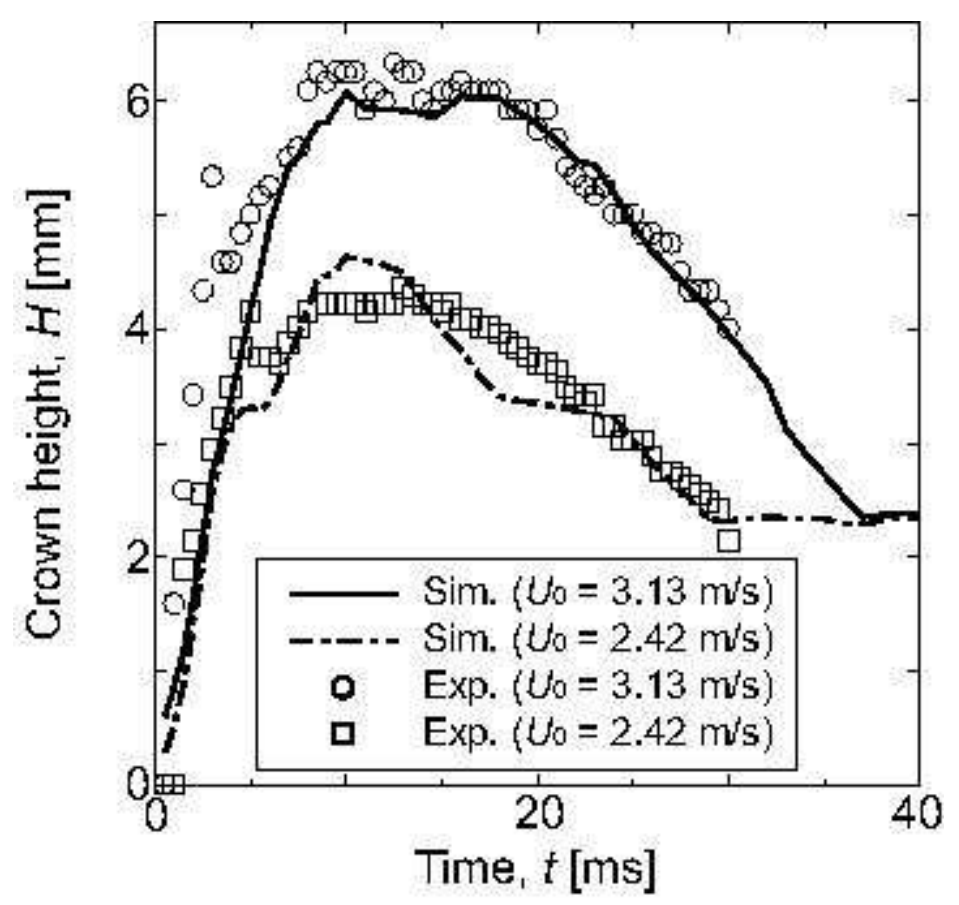

Comparison of crown height between simulation and experiment. $125 \times 118 \mathrm{~mm}(72 \times 72 \mathrm{DPI})$ 


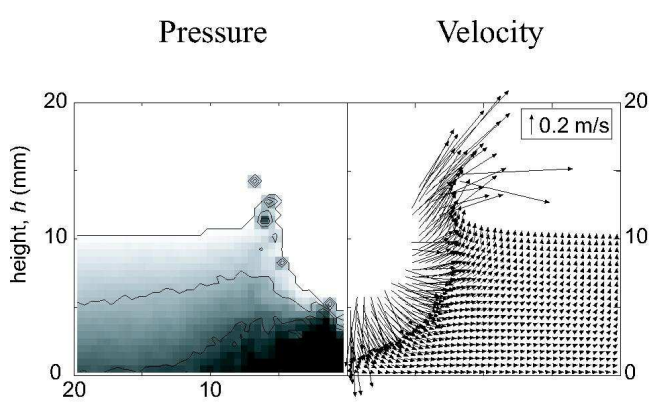

(a) $5 \mathrm{~ms}$

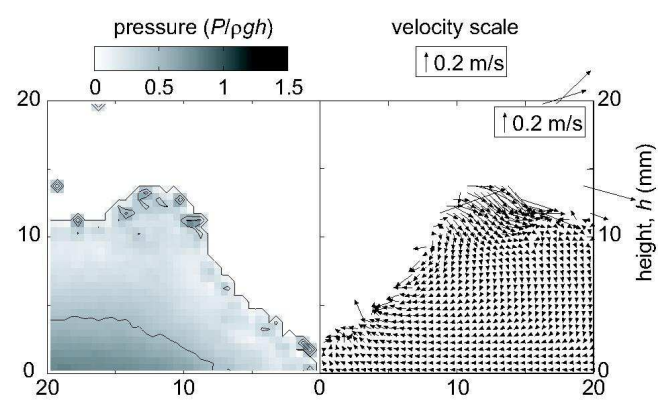

(d) $30 \mathrm{~ms}$

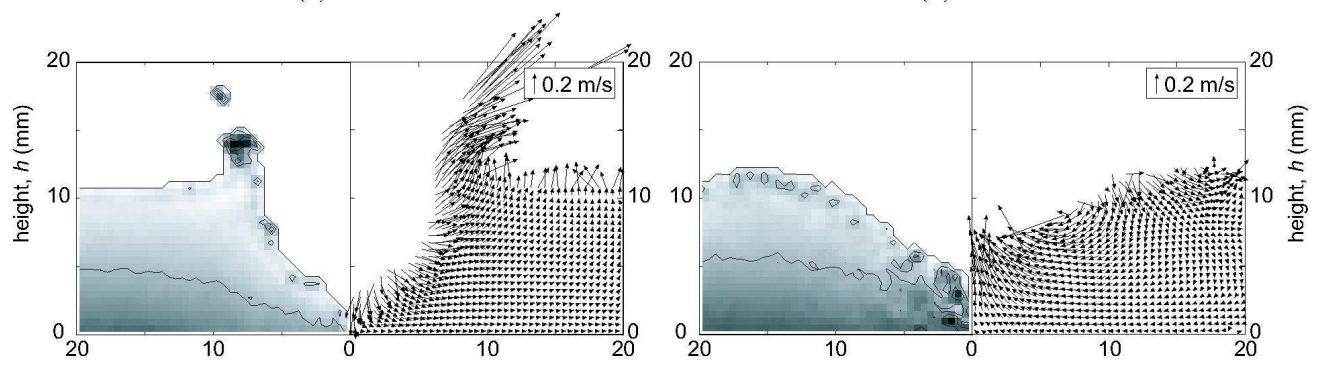

(b) $10 \mathrm{~ms}$

(e) $40 \mathrm{~ms}$

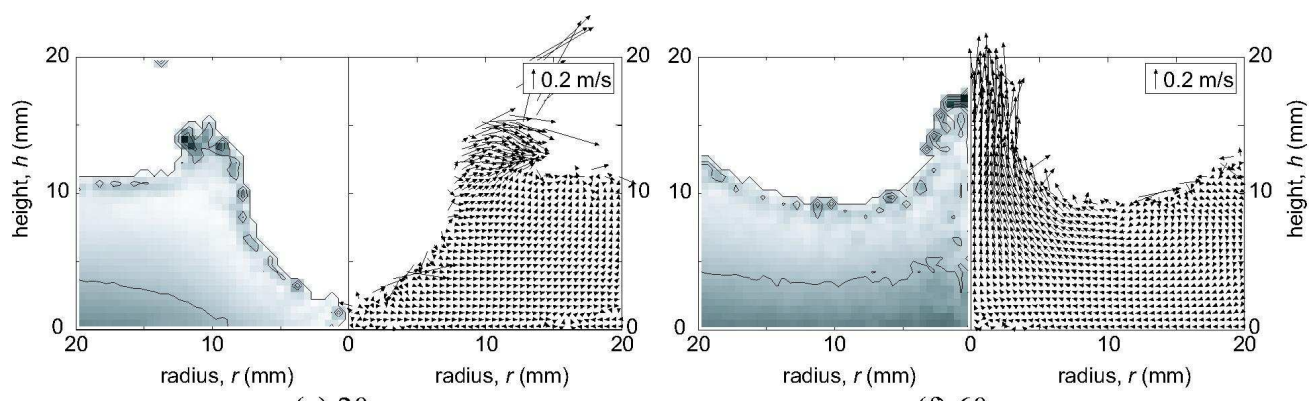

(c) $20 \mathrm{~ms}$

(f) $60 \mathrm{~ms}$

Axi-symmetric pressure and velocity fields upon droplet impact onto a liquid surface corresponding to the simulation in Figure $1\left(U_{0}=3.13 \mathrm{~m} / \mathrm{s}\right)$. $684 \times 663 \mathrm{~mm}(72 \times 72 \mathrm{DPI})$ 


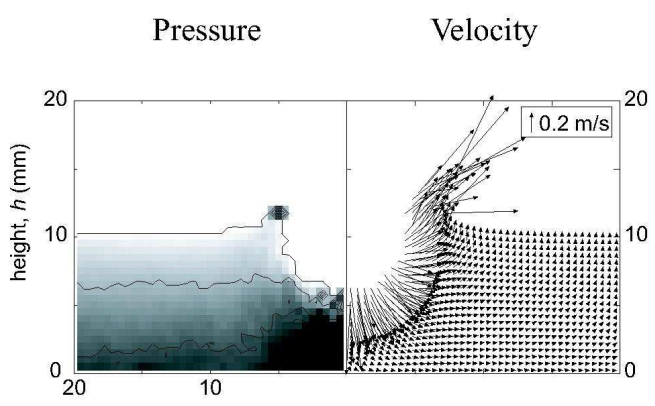

(a) $5 \mathrm{~ms}$

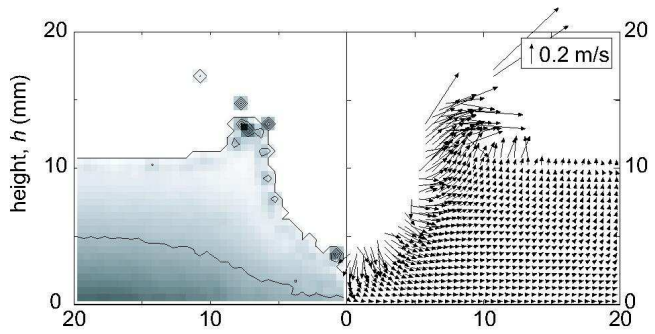

(b) $10 \mathrm{~ms}$

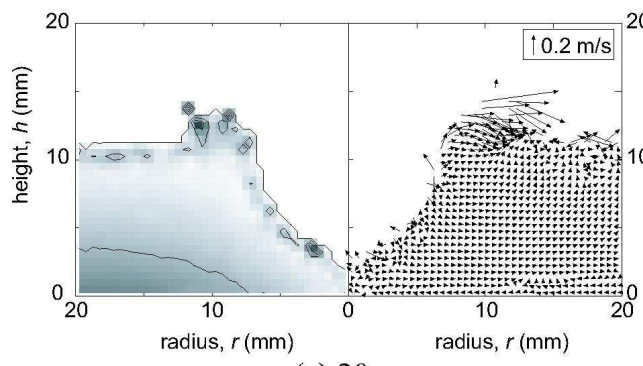

(c) $20 \mathrm{~ms}$

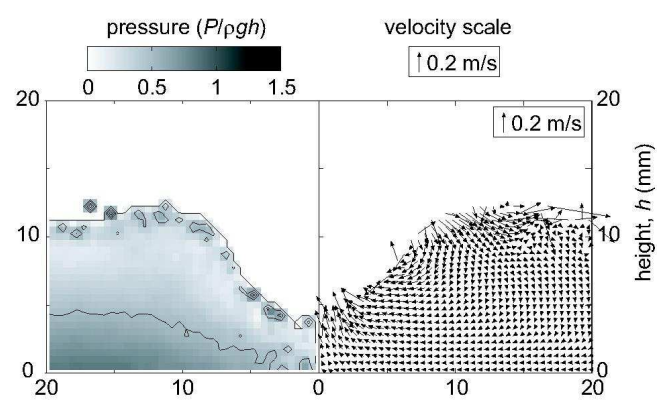

(d) $30 \mathrm{~ms}$

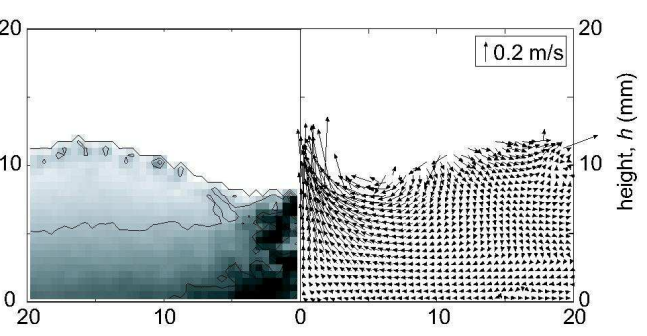

(e) $40 \mathrm{~ms}$

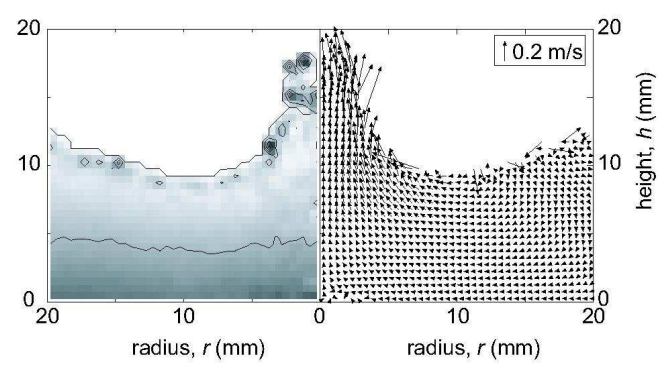

(f) $60 \mathrm{~ms}$

Axi-symmetric pressure and velocity fields upon droplet impact onto a liquid surface corresponding to the simulation in Figure $3\left(U_{0}=2.42 \mathrm{~m} / \mathrm{s}\right)$. $684 \times 663 \mathrm{~mm}(72 \times 72 \mathrm{DPI})$ 